\title{
Tradición y Progreso (1872-2012)
}

\author{
HUMBERTO REYES B. ${ }^{1}$, JOAQUÍN PALMA H. ${ }^{2}$, MAX ANDRESEN H. ${ }^{2}$
}

\section{Tradition and Progress (1872-2012)}

The first issue of Revista Médica de Chile appeared in July, 1872. Since then it has been published monthly and thus it became one of the oldest medical journals being printed since the $19^{\text {th }}$ Century. The opening Editorial in the first issue, labeled as "Prospecto" and written by the firsteditor, Germán Schneider, M.D., is reproduced. The current Editors comment the main statements found in that document establishing the purpose and scope of this journal. There are good reasons to sustain that through its 140 years of life, Revista Médica de Chile has fully accomplished the expectations of its founders and the owning institution: Sociedad Médica de Santiago-Chilean Society of Internal Medicine. The journal is serving well the medical community as a forum to present and discuss clinical experience, topics in scientific and technological advances related to medicine, medical education, medical ethics, and public health.

(Rev Med Chile 2012; 140: 837-840).

Key words: Education, medical; Chile; History of Medicine; Journalism, medical.

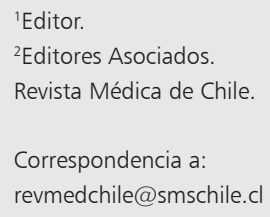

$\mathrm{E}$ n esta fecha -julio de 2012- se cumplen ciento cuarenta años desde la publicación del primer número de la Revista Médica de Chile. Su primer Director fue el Dr. Germán Schneider. Nacido en 1820, en Magdeburg, Alemania, con título de médico otorgado por la Universidad de Bonn, el Dr. Schneider emigró a Chile en 1850, para atender a los colonos alemanes en la zona Sur del país. Años después se trasladó a Santiago, donde ejerció su profesión, junto con labores académicas en la Universidad de Chile, como Profesor de Medicina. Fue un activo miembro de la Sociedad Médica de Santiago e impulsó la creación de la Revista, acompañado por un grupo de médicos entre los cuales destacaron los Dres. Adolfo Murillo, Alfonso Thévenot, Adolfo Valderrama, Pablo Zorrilla, y un sabio naturalista, además de médico, don Rodulfo A. Philippi ${ }^{1-3}$.

Siendo muy pocas las revistas médicas fundadas en el Siglo XIX que se han mantenido vigentes hasta hoy, cabe preguntarse cuál fue la fortaleza de los principios en que se basaron sus fundadores $y$ el propósito que le asignaron. Luego puede analizarse si ello ha seguido cumpliéndose, según la intención original.

El artículo editorial que encabezó el primer número de la Revista es la mejor guía para este análisis ${ }^{4}$. Su autor, el Dr. Schneider, lo tituló "Prospecto", palabra cuya segunda acepción en el Diccionario de la Real Academia Española indica "Exposición o anuncio breve que se hace al público sobre una obra, un escrito, un espectáculo, una mercancía, etc.". A continuación se reproducen párrafos seleccionados de ese artículo, respetando su ortografía original, propia del Siglo XIX. Solo se eliminaron algunas comas, que entorpecían la fluidez de su lectura:

\section{REVISTA MÉDICA}

Año 1. Santiago, julio de 1872, NUM. 1

\section{Prospecto}

Hace ya mucho tiempo que se ha reconocido la necesidad de fundar i sostener en esta capital un periódico que represente los intereses de las ciencias naturales, en jeneral, i especialmente de 1a medicina, en nuestro país. En diversas ocasiones se ha intentado hacerlo, pero o no han 
tenido resultado alguno estos esfuerzos o, si han llegado a tenerlo, el periódico que se ha organizado ha hecho una carrera corta i casi estéril. No entraré a investigar las causas de la inestabilidad de una publicación, cuya necesidad está en el pensamiento de todos: el desarrollo rápido que toman en el país las ciencias naturales i médicas; la importancia de estos estudios para el bienestar jeneral de la nación; la necesidad de que su cuerpo médico, numeroso e intelijente como es, tenga un medio de comunicarse recíprocamente los resultados de sus observaciones; los deberes que éste tiene de satisfacer las aspiraciones de la estudiosa juventud, que de día en día aumenta al rededor de las cátedras de medicina; todo nos obliga a desentendernos completamente del pasado i a fijar nuestra atención solamente en las exijencias del presente i en las esperanzas que debemos abrigar para el porvenir.

Un periódico de medicina i ciencias naturales, tal como ahora se piensa establecer, no solo será un bien para la ciencia, sino también para la sociedad en general, pues todo lo que se relaciona con la ciencia médica i su ejercicio es, por este mismo hecho, de un interés inmediato í directo para la sociedad entera. Ese periódico procurará la difusión de la ciencia, el esclarecimiento de cuestiones difíciles que muchas veces se presentan en la práctica de la profesión, la jeneralización de las nociones mas indispensables de hijiene pública i privada; él hará conocer el estado sanitario del país i se aplicará a dilucidar las cuestiones mas importantes de salubridad publica; él proporcionará datos estadísticos precisos sobre el movimiento de los hospitales en toda la República, dándonos una base fija para juzgar sobre las afecciones endémicas o epidémicas de mas fácil desarrollo entre nosotros; él, en fin, dará a conocer los trabajos del cuerpo médico, estableciendo esa comunicación de ideas que tantos beneficios reporta en los países en que existe. Tendrá también una sección destinada a hacer una revista bibliográfica o crítica, de las principales publicaciones estranjeras que tiendan al mismo objeto i que son de algún ínteres para la ciencia, o de una aplicación práctica.

Debiendo servir a los intereses de las ciencias médicas i naturales, sus columnas estarán pronto a recibir todos los artículos que tiendan a este objeto; con la precisa condición de que jamás abandonen el carácter respetable de la ciencia, para tomar el jiro de una polémica o un ataque personal. Cada artículo, por otra parte, debe traer la firma de su autor, quien será el único responsable de la doctrina que en él se desarrolle.

La redacción debe contar i cuenta con la participación abnegada i buena voluntad de todos los miembros del cuerpo médico del país, para que tengan a bien prestarle su jenerosa cooperación, pues solo bajo estas bases tendrá la Revista una vida robusta i llenará su objeto, que no es otro, como he dicho, que servir a la ciencia, al ejercicio de la profesión i así a los intereses mas nobles de la humanidad.

Al terminar este prospecto no puedo menos de dirijirme a todos los señores médicos del país, solicitando i exijiendo su cooperación para la Revista: los médicos de hospitales, los médicos de ciudad, los que tienen comisiones especiales del Gobierno o de las sociedades de beneficencia, los que se encuentran en situación de observar casos interesantes para la ciencia, todos pueden suministrar su continjente de luz i de saber; i a todos me dirijo suplicándoles, que presten a esta publicación su cooperación activa e intelijente.

En vista de los móviles que nos impulsan, i del fin que nos proponemos, me atrevo a esperar, que esta cooperación no nos faltará.

\section{Dr. Germán Schneider ${ }^{4}$}

Nuestro comentario como actuales Editores aludirá a seis puntos que identificamos como trascendentales en este documento, para la vida posterior de la Revista:

\section{1. "Necesidad de fundar y sostener un periódico que represente los intereses de la medicina $y$ de las ciencias, en Chile"}

De acuerdo con el progreso y la complejidad creciente de la medicina, la Sociedad Médica de Santiago dejó de ser la única sociedad científicoprofesional del país, para sedimentarse en la Sociedad Chilena de Medicina Interna. Sin embargo, sus subespecialidades se han mantenido como filiales o asociadas y se han creado vínculos con otras especialidades, en la interacción propia de la Asociación de Sociedades Científicas Médicas de Chile $^{5}$. Todas han tenido cabida en publicaciones en esta Revista, con artículos de interés médico general, que informan de un progreso científico con relevancia universal, o tratan de temas que podrían influir en la atención de pacientes adultos. El 
compromiso de la Revista con la educación médica y la salud pública en Chile es evidente para quien revise sus contenidos. Esto quedó fehacientemente documentado en el número de julio de 1972, dedicado a conmemorar su primer centenario y que puede considerarse un hito histórico en sus publicaciones.

\section{2. "Un cuerpo médico numeroso e inteligente que comunique los resultados de sus observaciones, fijando la atención en el presente y el porvenir"}

El número progresivo de manuscritos recibidos anualmente, que en 2011 superó 500, procede de una amplia gama de instituciones: universidades tradicionales y de creación reciente, hospitales públicos, clínicas privadas, hospitales de las Fuerzas Armadas, centros de salud y laboratorios privados. La variedad de autores de estos manuscritos y la de su procedencia institucional reflejan el interés general por tener tribuna en esta Revista.

\section{3. "Interés inmediato y directo para la sociedad"}

Que sean los editores de la revista quienes lo califiquen, es delicado porque puede considerarse que tienen un "conflicto de intereses", ya que son ellos quienes seleccionan los manuscritos que se publican, y rechazan los demás. Tal vez cabe mencionar que la Revista cuenta con el respeto de otros especialistas de la medicina, de las universidades nacionales, de sociedades científico-profesionales, y de entidades que promueven y financian la educación superior y la investigación científica (5). Además, en la página web en que se reproduce la Revista en formato electrónico (www.scielo. cl), queda constancia del número acumulado de "visitas" que tuvo cada artículo publicado.

\section{4. "Que los artículos publicados jamás abando- nen el carácter respetable de la ciencia”}

A medida que en las últimas décadas se han ido precisando los pilares de la ética en las publicaciones científicas, esta Revista los ha incorporado en su práctica e impone a los autores y revisores de manuscritos un respeto irrestricto a ellos: Integridad, Honestidad, Responsabilidad ("Accountability"), Transparencia.

5. "Participación abnegada y buena voluntad de los médicos del país. Me atrevo a esperar que esta cooperación no nos faltará.”
Su "atrevimiento" se ve nítidamente satisfecho por la labor desinteresada y abnegada de los especialistas consultados en el proceso de "revisión por pares". En el año 2011 se recibieron informes de 587 revisores externos, personas cuyas opiniones estimularon el perfeccionamiento de los manuscritos recibidos y apoyaron a los editores en su selección. Desde que se inició este proceso, en la década de 1970, la variedad de especialistas que intervienen es creciente, tal como lo requiere la complejidad progresiva de los manuscritos recibidos.

\section{6. "Una vida robusta que implica su propósito} de servir a la ciencia, al ejercicio de la profesión y los intereses más nobles de la humanidad."

La vitalidad de una revista médica exige contar con un equipo editorial cohesionado, que conozca su oficio y lo ejecute con independencia, buen criterio y espíritu de superación, apoyado por un equipo administrativo que disponga, a su vez, de recursos técnicos que se están haciendo más y más sofisticados. La época de los estafetas y del correo en papel ha sido sustituida por recursos electrónicos y la Internet. Es considerablemente alto el presupuesto que se necesita para publicar y distribuir una revista impresa, con periodicidad mensual, que difunde más de veinte manuscritos por número, incluyendo tablas con datos y figuras, a veces en colores, y con una solvencia ejemplar por cuanto la frecuencia de aclaraciones posteriores o "fe de errata" que se le solicitan es ínfima. Actualmente este presupuesto es asumido en su mayor proporción por la Sociedad Médica de Santiago. En ella recae, también, el mérito de sustentar una publicación que puede enorgullecer a sus dirigentes y miembros ${ }^{6}$.

Confiamos en que los principios sustentados en el "Prospecto" del Dr. Schneider han sido cumplidos satisfactoriamente por los distinguidos editores que nos han precedido y a quienes tratamos de emular ${ }^{7}$. Por eso, encabezamos esta Editorial con un título acuñado en 1973 por nuestro Editor Emérito y que ha sido un lema reiterado, veinte y veintisiete años después ${ }^{8-10}$.

\section{Referencias}

1. Costa-Casaretto C. ¿Quiénes crearon la Sociedad Médica de Santiago y la Revista Médica de Chile? Rev Med Chile 1972; 100: 769-804. 
2. Reyes H, Kauffmann R, Andresen M. Homenaje al Dr. Germán Schneider, primer Editor de la Revista Médica de Chile. Rev Med Chile 1997; 125(7): 761-4.

3. Goic A. La Revista Médica de Chile y la educación en medicina. Rev Med Chile 2002; 130: 719-22.

4. Schneider G. Prospecto. Rev Med Chile 1872; 1: 1-4.

5. Larraín Aguirre C. La Sociedad Médica de Santiago y el desarrollo histórico de la Medicina en Chile. Imprenta Salesianos, 2002.

6. Reyes H, Andresen M, Palma J. El aniversario 140 de la Revista Médica de Chile. Rev Med Chile 2012; 140:
7-9.

7. Goic A. Directores y Comités de Redacción de la Revista Médica de Chile (1872-1972). Rev Med Chile 1972; 110: 922-7.

8. Goic A, Reyes H. Tradición y Progreso. Rev Med Chile 1973; 101: 111-5.

9. Goic A, Reyes H. De 1872 a 1993: Tradición y Progreso. Rev Med Chile 1993; 121: 607-8.

10. Reyes H, Kauffmann R, Andresen M. Tradición y Progreso: ¿Ahora también una revista bilingüe? Rev Med Chile 2000; 128: 1187-9. 